\title{
General Psychiatry Delaying clozapine: how long is too long?
}

To cite: Varghese M T, Jyothi KS, Shaji KS, et al. Delaying clozapine: how long is too long? General Psychiatry 2020;33:e100172. doi:10.1136/ gpsych-2019-100172

Received 21 October 2019 Revised 08 March 2020 Accepted 23 March 2020
Check for updates

(C) Author(s) (or their employer(s)) 2020. Re-use permitted under CC BY-NC. No commercial re-use. See rights and permissions. Published by BMJ.

1Department of Psychiatry, Government Medical College Thrissur, Thrissur, Kerala, India ${ }^{2}$ Department of Psychiatry, General Hospital Kozhikode, Kozhikode, Kerala, India

${ }^{3}$ School of public health, University of California, Berkeley, California, USA

Correspondence to

Dr Tom Varghese M; tomvmalayil@gmail.com

Tom Varghese M (D) , ${ }^{1,2}$ KS Jyothi, ${ }^{1}$ KS Shaji, ${ }^{1}$ Lekshmi Rita Venugopal (D) ${ }^{3}$

\begin{abstract}
Background Although clozapine is the most effective drug for treatment-resistant schizophrenia, its use remains restricted in clinical practice in India. The delay in initiating treatment with clozapine and its impact on disease outcome needs evaluation.

Aim To identify the implications of delaying clozapine initiation in clinical outcomes among people with treatment-resistant schizophrenia.
\end{abstract}

Methods Subjects with treatment-resistant schizophrenia, stabilised on clozapine monotherapy, were recruited from the outpatient clinic of a general hospital psychiatry unit offering tertiary care services in Thrissur district, Kerala, India. A retrospective cohort design was employed, and information on duration of illness, total duration of treatment and duration of treatment with clozapine was collected. Present symptom status was measured using the Positive and Negative Syndrome Scale. Factors associated with higher symptom scores were analysed using an independent sample $t$ test, Spearman correlation and multiple linear regression.

Results Forty subjects stabilised on long-term clozapine therapy formed the study sample. The mean dose of clozapine used in the study population was $200 \mathrm{mg}$. The mean duration of antipsychotic treatment before starting clozapine was 89.3 months (7.4 years). The duration of treatment before starting clozapine was found to have a significant positive association with the total Positive and Negative Syndrome Scale score (correlation coefficient $0.40 ; p=0.01$ ) and negative symptom score (correlation coefficient $0.33 ; p=0.04$ ). The multiple regression analysis adjusting for covariates showed that the duration of treatment before starting clozapine was an independent factor associated with a higher negative symptom score in the Positive and Negative Syndrome Scale (slope $\beta=0.05$; $p=0.02 ; R^{2}=0.27$ ).

Conclusion Poor treatment outcomes in treatmentresistant schizophrenia could be secondary to a delay in initiating clozapine therapy.

\section{INTRODUCTION}

Schizophrenia affects about $1 \%$ of the general population and is a leading cause of disability. Pharmacotherapy with antipsychotic drugs remains the mainstay in the management of schizophrenia. However, about 30\% of patients respond poorly to adequate doses of conventional first-line antipsychotic drugs and about $7 \%$ show no response. ${ }^{1}$ Treatment resistance is defined as the failure to respond to at least two first-line antipsychotic drugs in adequate doses for a period of 6 weeks. ${ }^{2}$

Clozapine, a second-generation antipsychotic, is found to be most effective in managing treatment-resistant cases of schizophrenia. ${ }^{3}$ This effectiveness may be attributed to its unique, yet not fully understood, mechanism of action on neuronal receptors. Clozapine is also known to cause potentially fatal side effects such as agranulocytosis, myocarditis and cardiomyopathy. Despite its side effect profile, treatment with clozapine is known to reduce the overall mortality in schizophrenia, mainly by lowering the risk of suicide. ${ }^{4}$

Even though there is strong evidence in favour of its use in treatment-resistant schizophrenia, the actual use of clozapine remains limited in clinical practice. ${ }^{5}$ There is substantial delay in initiating clozapine worldwide, and high-dose antipsychotic therapy and polypharmacy are often resorted to before initiation of clozapine therapy. ${ }^{6}$

We wanted to study the profile of patients on long-term clozapine monotherapy from a general hospital psychiatry unit to identify the delay in starting clozapine therapy for managing treatment-resistant schizophrenia and if that had impacted the overall clinical outcome. We looked at the duration of treatment with antipsychotics before starting clozapine to see if they were associated with poor outcome among these patients.

\section{MATERIALS AND METHODS}

The study was conducted from a general hospital psychiatry unit offering tertiary care services in Thrissur district, Kerala, after getting approval from the Institutional Ethics Committee.

We identified outpatients of the department of psychiatry on 3 fixed days of the week from January 2016 to January 2017. On the basis of previous literature, ${ }^{7}$ the sample size required to detect the expected deviation of correlation from zero with a type 1 error/alpha set at 0.05 and power at 0.8 was calculated to be 
$36 .{ }^{8}$ Hospital records were reviewed and patients meeting the International Classification of Diseases- 10 diagnosis of schizophrenia, who were currently on a stable dose of clozapine for more than 8 weeks and had symptom stability for a minimum period of 6 weeks were included in the study. Symptom stability was defined as no change in the Clinical Global Impression (CGI) severity of illness score for at least 6 consecutive weeks. Subjects receiving other antipsychotics and those with significant disabling comorbidities such as neurodegenerative disorders or mental retardation were excluded.

Subjects and their caregivers were interviewed, and sociodemographic details were collected.

The Modified Kuppuswamy Scale was used to measure socioeconomic status. ${ }^{9}$ Information regarding the age of onset of schizophrenia, duration of illness, duration of treatment with antipsychotics other than clozapine, duration of treatment with clozapine, current dose of clozapine and history of smoking was retrieved from hospital records. Duration of untreated psychosis (period from the onset of illness to initiation of antipsychotic treatment) was also calculated. Duration of treatment before starting clozapine was defined as the period from the initiation of antipsychotic treatment to the onset of clozapine treatment.

The primary outcome was quantified using the Positive and Negative Syndrome Scale (PANSS) and CGI severity scale. Secondary outcomes were measured using CGIglobal improvement and CGI-efficacy index. Assessments were performed by clinicians trained in psychiatry who were blinded to the clozapine status of the patient.

\section{Measures}

\section{Positive and Negative Syndrome Scale}

PANSS has been widely used in clinical research for rating symptom severity in patients with schizophrenia since it was first published in 1987 by Kay et al. ${ }^{10}$ The scale consists of 30 items pertaining to the positive, negative and general psychopathology scale. Each of the items was scored from 1 to 7 points, totalling up to scores ranging from 30 to 210. PANSS is well characterised, standardised and sensitive to treatment response. ${ }^{11}$

\section{Clinical Global Impression Scale}

The CGI is a widely used subjective scale performed by experienced clinicians and researchers. It provides a global perspective on symptom severity, response to treatment and efficacy. ${ }^{12}$ Severity is rated relative to past clinical experiences with patients who have the same diagnosis. CGI-global improvement is rated by comparing the patient's present condition with that at the beginning of the treatment. The CGI-efficacy index incorporates both therapeutic effects and side effects of the treatment.

\section{Statistical analysis}

Patients were assigned into low and high symptom severity groups based on the PANSS scores. Low symptom score was defined as a PANSS score less than 58 based on previous studies. ${ }^{313}$ Various factors associated with a

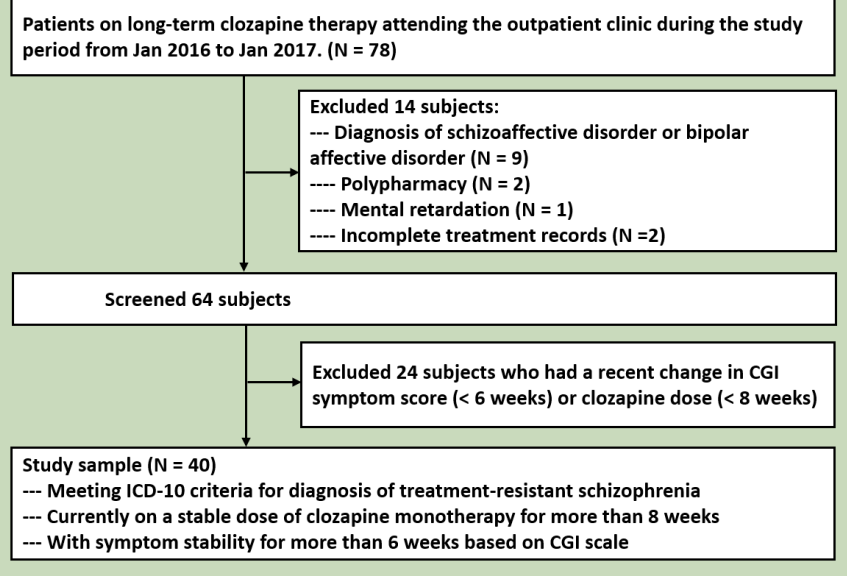

Figure 1 CONSORT diagram. CGI, Clinical Global Impression; CONSORT, Consolidated Standards of Reporting Trials; ICD-10, International Classification of Diseases 10.

higher PANSS score were identified using independent sample $t$ test. These factors were further evaluated using spearman's correlation and multiple linear regression analyses. Multiple regression analysis for the relationship between each component of PANSS (positive, negative and general psychopathology scale) and delay in intiating clozapine was done adjusting for coviariates like age of onset of schizophrenia, duration of untreated psychosis, duration of illness and clozapine dose used. Statistical analysis was done using $\mathrm{R}$ statistical software. ${ }^{14}$

\section{RESULTS}

During the 1-year study period, 78 patients were identified to be on long-term clozapine treatment. We recruited 40 patients who met the study criteria. Reasons for exclusion were recent change in symptom score or clozapine dose (24 subjects) and diagnosis of a schizoaffective disorder or bipolar affective disorder (9 subjects). Two subjects were on another antipsychotic drug along with clozapine and one patient had mental retardation. Two patients on clozapine were excluded due to incomplete treatment records (figure 1).

The mean age of the study population was 33 (10) years. Most of the subjects were men $(82 \%)$. The majority of the subjects $(75 \%)$ were without life partners, and $90 \%$ of them belonged to a low socioeconomic status. All patients had received some level of formal education.

The mean age of onset of schizophrenia in the study population was $20.6(6.8)$ years. The average duration of illness was 13.5 years. Most subjects $(62.5 \%)$ had a low score on the CGI severity scale $(\mathrm{CGI}<4)$, and $67 \%$ showed a low symptom score in PANSS $(<58)$. As expected, all patients showed some level of improvement. Of the patients, $40 \%$ scored 'very much improved' and 57.5\% scored 'much improved' on the CGI improvement scale. According to the CGI-efficacy index, $25 \%$ of patients reported no side effects and $70 \%$ reported side effects that did not 
Table 1 Descriptive parameters of patients on long-term stable clozapine monotherapy

\begin{tabular}{|c|c|c|}
\hline Descriptive parameters & Mean & SD \\
\hline Age (years) & 33.75 & 10.04 \\
\hline Age of onset of schizophrenia (years) & 20.68 & 6.83 \\
\hline Duration of untreated psychosis (months) & 39.86 & 52.45 \\
\hline $\begin{array}{l}\text { Duration of treatment prior to starting } \\
\text { clozapine (months) }\end{array}$ & 89.28 & 87.84 \\
\hline $\begin{array}{l}\text { Duration of treatment with clozapine } \\
\text { (months) }\end{array}$ & 47.23 & 47.07 \\
\hline Present clozapine dose (mg) & 192.5 & 114.8 \\
\hline
\end{tabular}

interfere with functioning. Only $5 \%$ of patients reported significant side effects.

\section{Treatment characteristics}

About half $(47.5 \%)$ of the patients did not receive any treatment for more than 1 year after the onset of symptoms and 3 patients remained untreated for more than 5 years. The mean duration of treatment before starting clozapine was found to be 89.3 (87.8) months. The average clozapine dosage in the study population was $200 \mathrm{mg}$ per day. The dose received ranged from 25 to $500 \mathrm{mg}$. Of the subjects, $77.5 \%$ were found to be clinically stable on clozapine doses between 100 and $300 \mathrm{mg}$. Table 1 shows the descriptive parameters of patients on long-term stable clozapine monotherapy.

\section{Factors associated with severity}

The study population was divided into low and high symptom severity groups based on the PANSS scores. Analysis for the association with clinical outcome was done using independent sample $t$ tests. The duration of treatment before starting clozapine was associated with a poor clinical outcome, as indicated by a significantly higher PANSS score among patients with high symptom severity (mean difference $=67.52$; 95\% CI: 2.31 to 132.71 ; $\mathrm{p}=0.04$ ). However, variables such as duration of untreated psychosis, gender, age of onset of illness, duration of illness and duration of treatment did not show a significant association with clinical outcome. Table 2 shows the results of independent sample $t$ test for analysis of the association between various factors and clinical outcome.

\section{Tests of association}

The Spearman rank correlation analysis revealed a positive association between the duration of treatment with antipsychotic drugs before starting clozapine with both the total PANSS score (correlation coefficient 0.40; $\mathrm{p}=0.01$ ) and negative symptom score in PANSS (correlation coefficient $0.33 ; \mathrm{p}=0.04)$. The clozapine dose required to stabilise the symptoms also showed a positive correlation with the total PANSS score (correlation coefficient $0.47 ; \mathrm{p}=0.002$ ). However, there was no significant correlation between the duration of treatment before starting clozapine and the positive symptom score and global psychopathology scale components of PANSS. The duration of untreated psychosis did not demonstrate any significant correlation to the PANSS score in our study population (table 3 ).

\section{Regression analysis}

The multiple regression analysis adjusting for covariates such as duration of untreated psychosis, age of onset of schizophrenia, clozapine dose used to stabilise the symptoms and total duration of illness demonstrated a significant positive correlation between the negative symptom score in PANSS and the duration of treatment before starting clozapine (slope $\beta=0.05 ; \mathrm{p}=0.04 ; 95 \%$ CI : 0.004 to $0.089 ; \mathrm{R}^{2}=0.27$ ) (figure 2). However, the multiple regression analysis adjusting for covariates could not replicate a significant association between the total PANSS score and duration of treatment before starting clozapine. The delay in starting clozapine therapy was found to be

Table 2 Independent sample $t$ test for analysis of the association between various factors and PANSS

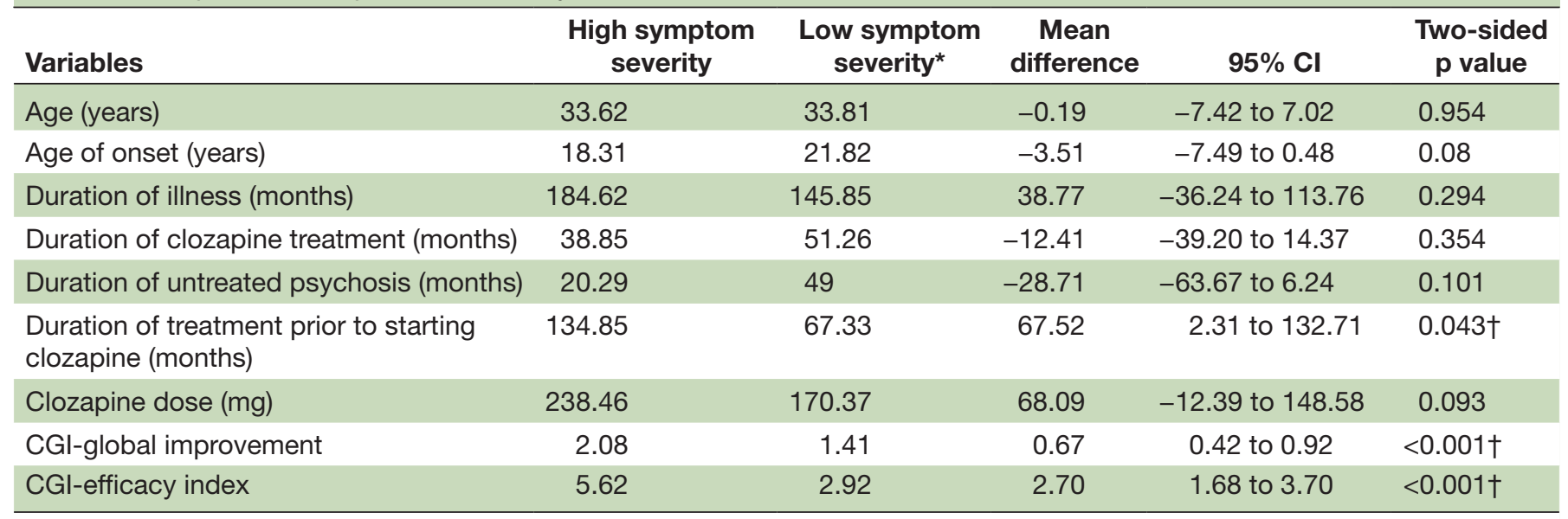

*Low symptom severity defined as PANSS $<58$.

† Significance at $p<0.05$

CGI, Clinical Global Impression; PANSS, Positive and Negative Syndrome Scale. 
Table 3 Correlation matrix

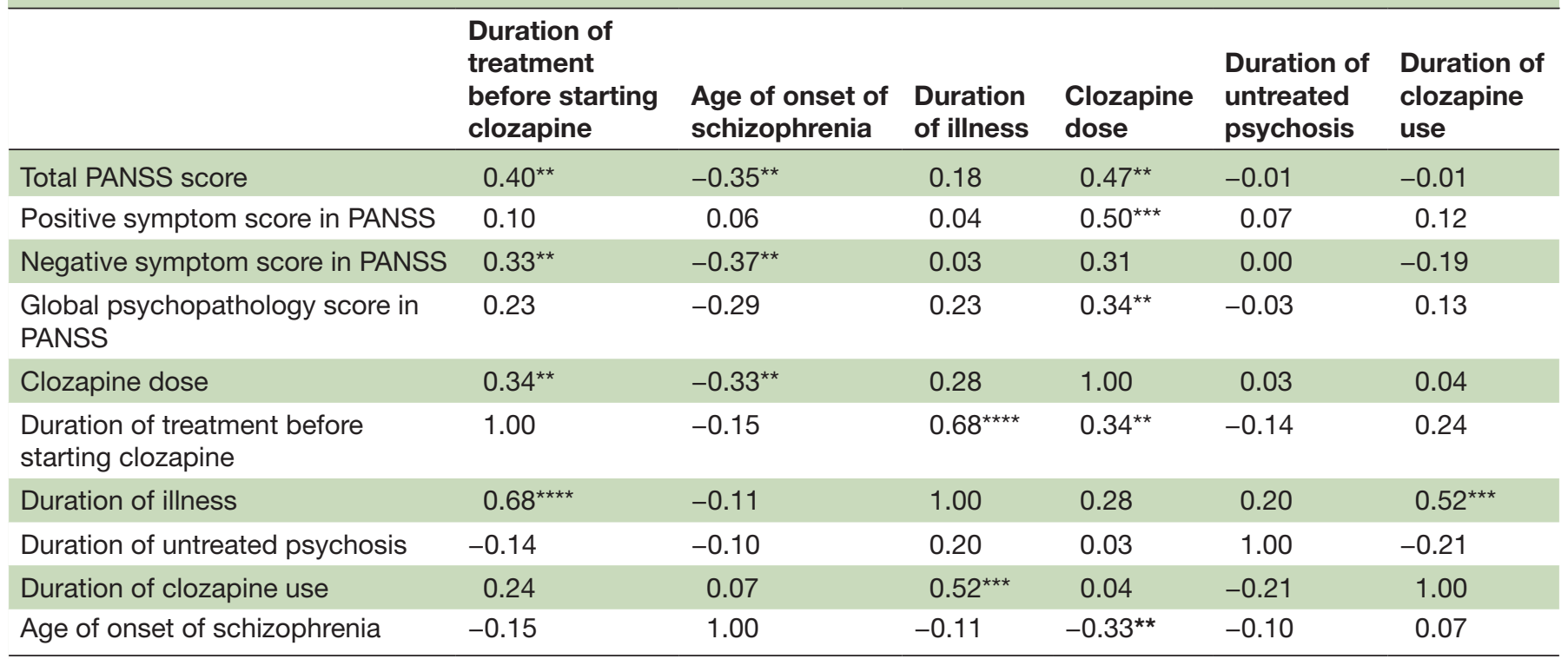

${ }^{\star \star \star \star *} \mathrm{P}<0.001,{ }^{\star \star \star} \mathrm{p}<0.01,{ }^{* \star} \mathrm{p}<0.05$

PANSS, Positive and Negative Syndrome Scale.

an independent factor associated with a higher negative symptom score in PANSS.

\section{DISCUSSION}

\section{Main findings}

The mean duration of treatment with other antipsychotics before the initiation of clozapine therapy was 7.4 years. Wheeler ${ }^{15}$ reported a mean duration of 9.7 years of treatment with antipsychotics before clozapine was initiated in their patients. Other studies have focused mainly on 'theoretical delay' in starting clozapine. ${ }^{16}$ Theoretical delay was measured from the point when cases met the diagnostic criteria for treatment-resistant schizophrenia (poor response to two adequate antipsychotic trials given for 6 weeks each) to the point of initiation of clozapine. Howes $e t a l^{8}$ reported a mean theoretical delay of 4 years. A similar study from India by Grover et $a l^{17}$ reported a

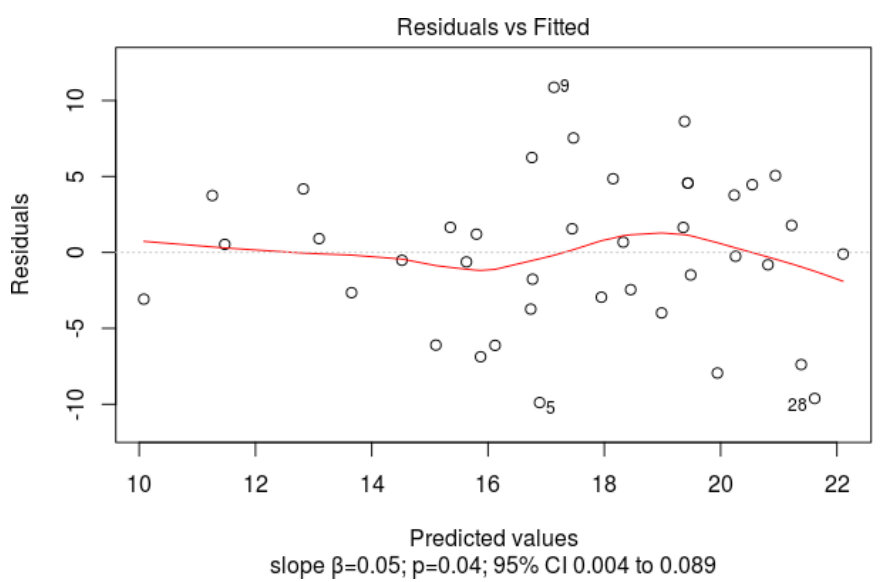

Figure 2 Duration of treatment before starting clozapine and negative symptom score in the Positive and Negative Syndrome Scale. mean delay of 2 years. We could not evaluate the theoretical delay as most of our subjects did not receive sequential antipsychotic trials. Many of the subjects had prolonged treatment with higher doses, and the use of polypharmacy was commonly encountered before initiation of the second antipsychotic trial. We therefore thought that the calculation of theoretical delay by the existing method would not be useful and thus we did not pursue the same.

There could be many reasons for the delay in initiating clozapine therapy. Concerns regarding tolerability and refusal for regular blood monitoring could be important factors. ${ }^{18}$ Howes $e t a l^{8}$, while reporting the frequent use of polypharmacy and higher than recommended doses of antipsychotics before initiation of clozapine, commented that the delay in initiation of clozapine therapy was often due to non-adherence to the guidelines by the clinicians. Resource limitations, non-availability of mental health professionals and additional costs for frequent follow-ups and blood tests could be other barriers to early initiation of clozapine therapy.

\section{Factors affecting treatment outcome}

Our analysis found the duration of treatment with other antipsychotics before starting clozapine was the only factor significantly associated with higher negative symptom scores after adjustment for potential covariates. Üçok $e t a l^{19}$ had reported delay in starting clozapine and a higher clozapine dose as independent contributors towards response to clozapine. Perkins $e t a l^{20}$ in a review concluded that the duration of untreated psychosis is a potentially modifiable prognostic indicator, and Lieberman $e t a l^{21}$ found early age of onset and female gender to be predictors of poor response to clozapine. However, we could not find any significant association of PANSS 
scores with gender, age of onset or duration of untreated psychosis in our study.

\section{Clozapine dose}

The average daily dose of clozapine that this sample of clinically stable patients with treatment-resistant schizophrenia received was $200 \mathrm{mg}$. The dosage received ranged from 25 to $500 \mathrm{mg}$ per day, with most of them $(77.5 \%)$ getting 100 to $300 \mathrm{mg}$ per day. Our finding supports reports from India suggesting that a daily dosage of 150 to $300 \mathrm{mg}$ of clozapine is adequate for symptom control. ${ }^{22}$ Clinical trials done in India also used an average of 250 to $300 \mathrm{mg}$ of clozapine per day to achieve a response, ${ }^{2324}$ unlike the average doses reported from Europe and USA, which were higher. ${ }^{25}$ The doses reported by us refer only to the doses needed for maintenance of remission and thus do not indicate the doses needed for the control of symptoms in the initial phase of treatment.

\section{Strengths and limitations}

Unlike many previous studies, we studied patients stabilised on long-term clozapine monotherapy. We examined the association between the delay in starting clozapine and treatment outcome and looked at factors associated with poor outcomes following clozapine therapy. We found an association between clinical outcome and the duration of treatment before initiating clozapine therapy. Recall bias and interviewer bias could potentially affect the results of our study. We attempted to limit recall bias by a review of medical charts whenever available and interviewer bias by blinding the clinician performing PANSS assessments to the clozapine status of the patient. The small sample size and the study setting limit the generalisability of our findings.

\section{Implications}

We found an association between clinical outcome and the duration of treatment before clozapine initiation. Two possible explanations for this finding can be considered. Some patients could develop treatment resistance later in the course of the illness. This late-onset treatment resistance could indicate poor prognosis. Pharmacological modulation of the underlying neurophysiological substrate in these patients may not be effective, unlike those who manifest treatment resistance early in the course of the illness. The second possibility is one of nonresponse or poor response to clozapine therapy when there is a delay in initiating clozapine therapy in patients who need it. This would suggest that there is a window of opportunity in the management of treatment resistance in patients with schizophrenia and that could be lost by the delay in the initiation of treatment using clozapine. We need to examine both these possibilities in future studies addressing treatment resistance in schizophrenia. These findings, if replicated, can have implications for the management of treatment resistance in patients with schizophrenia.

\section{CONCLUSION}

The duration of pharmacological treatment before initiation of clozapine appears to be a potentially modifiable factor associated with treatment outcome. There is an emerging consensus for earlier initiation of clozapine in patients unresponsive to first-line antipsychotics. The role of delay in starting clozapine as an independent prognostic indicator in treatment-resistant schizophrenia merits further study. Barriers that lead to the delay in initiating clozapine therapy should be identified and dealt with.

Contributors JKS and SKS designed and supervised the study. TVM was involved in clinical assessments and data collection. LRV analysed the data. All authors contributed to drafting the report. The final manuscript was approved by all the authors.

Funding The authors have not declared a specific grant for this research from any funding agency in the public, commercial or not-for-profit sectors.

Competing interests None declared.

Patient consent for publication Obtained.

Ethics approval The study has been approved by Institutional Review Board, Government Medical College, Thrissur (approval number: B6-15426/2014/MCTCR).

Provenance and peer review Not commissioned; externally peer reviewed.

Data availability statement Data are available in a public, open access repository. Repository name: Open Science Framework. URL: https://mfr.osf.io/render?url= https://osf.io/wu4sp/?action=download\%26mode=renderReuse permitted

Open access This is an open access article distributed in accordance with the Creative Commons Attribution Non Commercial (CC BY-NC 4.0) license, which permits others to distribute, remix, adapt, build upon this work non-commercially, and license their derivative works on different terms, provided the original work is properly cited, appropriate credit is given, any changes made indicated, and the use is non-commercial. See: http://creativecommons.org/licenses/by-nc/4.0/.

ORCID iDs

Tom Varghese M http://orcid.org/0000-0001-6028-0137

Lekshmi Rita Venugopal http://orcid.org/0000-0001-8851-4986

\section{REFERENCES}

1 Itil TM, Keskiner A, Fink M. Therapeutic studies in "therapy resistant" schizophrenic patients. Compr Psychiatry 1966;7:488-93.

2 National Collaborating Centre for Mental Health (UK). Psychosis and schizophrenia in adults: treatment and management: updated edition 2014. London: National Institute for Health and Care Excellence, 2014.

3 Kane J, Honigfeld G, Singer J, et al. Clozapine for the treatmentresistant schizophrenic. A double-blind comparison with chlorpromazine. Arch Gen Psychiatry 1988;45:789-96.

4 Tiihonen J, Lönnqvist J, Wahlbeck K, et al. 11-year follow-up of mortality in patients with schizophrenia: a population-based cohort study (FIN11 study). The Lancet 2009;374:620-7.

5 Bachmann CJ, Aagaard L, Bernardo M, et al. International trends in clozapine use: a study in 17 countries. Acta Psychiatr Scand 2017;136:37-51.

6 Yada Y, Yoshimura B, Kishi Y. Correlation between delay in initiating clozapine and symptomatic improvement. Schizophr Res 2015;168:585-6.

7 Hulley SB CS, Browner WS, Grady D, et al. Designing clinical research : an epidemiologic approach. Lippincott Williams \& Wilkins, 2013.

8 Howes OD, Vergunst F, Gee S, et al. Adherence to treatment guidelines in clinical practice: study of antipsychotic treatment prior to clozapine initiation. Br J Psychiatry 2012;201:481-5.

9 Shaikh Z, Pathak R. Revised Kuppuswamy and B G Prasad socioeconomic scales for 2016. Int J Community Med Public Health 2017;4:997.

10 Kay SR, Fiszbein A, Opler LA. The positive and negative syndrome scale (PANSS) for schizophrenia. Schizophr Bull 1987;13:261-76. 
11 Opler MGA, Yavorsky C, Daniel DG. Positive and negative syndrome scale (PANSS) training: challenges, solutions, and future directions. Innov Clin Neurosci 2017;14:77-81.

12 Busner J, Targum SD. The clinical global impressions scale: applying a research tool in clinical practice. Psychiatry 2007;4:28-37.

13 Leucht S, Kane JM, Kissling W, et al. What does the PANSS mean? Schizophr Res 2005;79:231-8.

14 R Core Team. R: a language and environment for statistical computing. Vienna, Austria: R Foundation for Statistical Computing, 2019.

15 Wheeler AJ. Treatment pathway and patterns of clozapine prescribing for schizophrenia in New Zealand. Ann Pharmacother 2008;42:852-60.

16 Shah P, Iwata Y, Plitman E, et al. The impact of delay in clozapine initiation on treatment outcomes in patients with treatment-resistant schizophrenia: a systematic review. Psychiatry Res 2018;268:114-22.

17 Grover S, Hazari N, Chakrabarti S, et al. Delay in initiation of clozapine: a retrospective study from a tertiary care hospital in North India. Psychiatry Res 2015;226:181-5.

18 Gee S, Vergunst F, Howes O, et al. Practitioner attitudes to clozapine initiation. Acta Psychiatr Scand 2014;130:16-24.
19 Üçok A, Çikrikçili U, Karabulut S, et al. Delayed initiation of clozapine may be related to poor response in treatment-resistant schizophrenia. Int Clin Psychopharmacol 2015;30:290-5.

20 Perkins DO, Gu H, Boteva K, et al. Relationship between duration of untreated psychosis and outcome in first-episode schizophrenia: a critical review and meta-analysis. Am J Psychiatry 2005;162:1785-804.

21 Lieberman JA, Kane JM, Safferman AZ, et al. Predictors of response to clozapine. J Clin Psychiatry 1994;55:126-8.

22 Shrivastava A, Shah N. Prescribing practices of clozapine in India: results of a opinion survey of psychiatrists. Indian J Psychiatry 2009;51:225-6.

23 Desai N, Jain V, Ghalsasi S, et al. An open study of clozapine in the treatment of resistant schizophrenia. Indian J Psychiatry 1999;41:336-40.

24 Srivastava S, Agarwal A, Sharma M. A three-year naturalistic followup of patients receiving clozapine: report from India. Int J Psychiatry Clin Pract 2002;6:167-71.

25 Fleischhacker WW, Hummer M, Kurz M, et al. Clozapine dose in the United States and Europe: implications for therapeutic and adverse effects. J Clin Psychiatry 1994;55:78-81.

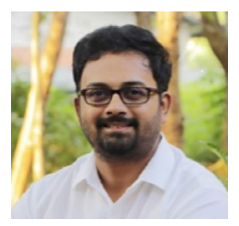

Dr. Tom Varghese M is a consultant psychiatrist at the General Hospital Calicut, Kerala, India. He is the head of the district level de-addiction and rehabilitation centre at Calicut Beach Hospital, run under the combined efforts of the Ministry of Health and Excise. His work focuses on a comprehensive approach to addiction management, incorporating an integrated model of care. His research interests include the exploration of epigentic associations of psychiatric and medical co-morbidities and pharmacotherapeutic moduation in the course of mental health disorders, specifically involving management of psychosis and substance abuse disorders. 